\title{
Factors Associated With Timely Initiation Of Breastfeeding Among Mothers In JPMC
}

\author{
Beena Barkat Ali, Shazia Naseeb, Razia Korejo
}

ABSTARCT

Objective: Study the frequency of common factors Associated with timely initiation of breastfeeding.

Study design: Descriptive Cross sectional.

Duration and place of study: this study was conducted at, Jinnah postgraduate Medical center Karachi unit-I from 19 May to 18 November 2015.

Material \& Methods: A total of 108 mother infant pairs were selected by Non probability consecutive sampling technique, meeting our inclusion criteria. Informed consent was taken after explaining the pros and cons, purpose and procedure of the study. The common factors associated with timely initiation of breastfeeding like age of the mother, gestational age, parity, educational status, working status of the mother, mode of delivery, birth weight of the baby and gender of the baby were evaluated through face to face interview of the mothers .

Results: In our study mean age of mothers found to be 26.1 years old. Mean birth interval found to be 3.1years. Mean birth weight of the babies was $2.86 \mathrm{~kg}$. Mean gestational age of the Patients was 38.1 weeks. Most of the babies were female $63(58 \%)$ other were male 45(42\%). Out of 108 patients, 40(37\%) received Primary education, $27(25 \%)$ were graduated, $18(17 \%)$ were Illiterate, $13(12 \%)$ secondary and $10(9 \%)$ were Intermediate. Thirty eight $(35.2 \%)$ belonged to middle class, $56(51.9 \%)$ to upper middle class and only $14(13 \%)$ to higher class. Fifty eight $(53.7 \%)$ women were multiparae and 76(70.3\%) were employed; And Mostly 66 (61\%) delivered through Cesarean -Section.

Conclusion: According to this study the main conclusion of Common factors associated to timely initiation of breastfeeding were age of mothers(74.07\%) more than 20years, parity 2 or more $(61.1 \%)$, educational level secondary and above $(50.9 \%)$, house wives (32.9\%), male sex of infant (41.6\%) and Vaginal mode of delivery $(38.8 \%)$

Keywords: Breastfeeding, Breastfeeding initiation, primigravidae, practices

\section{INTRODUCTION:}

Many women want to breastfeed but are unable to do so. Lack of confidence in their ability to breastfeed, problems with proper positioning of neonate, myths of inadequate milk supply, breast pain and lack of support from health professionals in early post discharge period are some reasons why breastfeeding is not initiated and if initiated is not continued for the recommended duration ${ }^{2}$.

Antenatal counseling and postnatal lactation support, improve rates of exclusive breastfeeding. There has been a substantial improvement over the past two decades in the proportion of mothers receiving antenatal care from a skilled health provider, increasing from $26 \%$ in $1990-91$ to 61 percent in $2006-07$ and $73 \%$ in $2012-13$. Antenatal visits provide an

Beena Barkat Ali,

I Postgraduate Student,

I Jinnah Post Graduate Medical Center, Karachi

I Shazia Naseeb,

Asscoiate Professor, Dept. of Gynaecology \& Obstetrics

Jinnah Post Graduate Medical Center, Karachi

I Email:snkhan1975@yahoo.com

I

Razia Korejo,

Professor, Dept. of Gynaecology \& Obstetrics

I Bahria University Medical \& Dental College, Karachi

I Received: 20-02-2018

I Revised: 30-04-2018

Accepted: 15-05-2018

(8) opportunity to educate women regarding the benefits of breastfeeding and can help improve rates of initiation of exclusive breastfeeding ${ }^{1-4}$.

Baby Friendly Hospital Initiative was launched in 1991 by $\mathrm{UNICEF}^{4}$ and $\mathrm{WHO}^{5}$ to ensure that all maternity services support breastfeeding. Ten steps to successful breastfeeding need to be implemented if a health facility wants to be accredited as Baby Friendly. Step 3 of these steps is 'inform all pregnant women about benefits and management of breastfeeding'. Implementation of baby friendly hospital initiative in Sindh, Pakistan improved breastfeeding practices in some of the centers to $98.97 \%$.

Breastfeeding practices in Pakistan are far from ideal. Ninetyfour percent of children were reported to have been breastfed at some time. $38 \%$ percent of children less than age 6 months are exclusively breastfed. The median duration of exclusive breastfeeding is less than one 1month. Complementary foods are not introduced in a timely fashion for all children. Only $57 \%$ of breastfed children age 6-9 months received complementary foods. Overall, only $15 \%$ of children ages 6-23 months are fed appropriately based on recommended infant and young child feeding (IYCF) practices².

Breastfeeding offers many advantages to the newborn and the new mother. Although emphasis is put on breastfeeding rates, even then, breastfeeding often fall short of the required frequency of breastfeeding. 
The $\mathrm{WHO}^{6}$ and American Academy of Pediatrics ${ }^{7}$ both recommend exclusive breastfeeding for six months and complementary feeding with breastfeeding for at least 12 or 24 months. In our study $78 \%$ of women who were counselled knew that exclusive breastfeeding needs to be practiced for first six months and only $35 \%$ knew that babies less than 6 months do not need extra water. Ahmad et al report $68 \%$ of women breastfeed exclusively after breastfeeding and Dhandapany et al report that more women practice exclusive breastfeeding after counselling ${ }^{8,9}$

The Pakistan Demographic and Health Survey ${ }^{2}$ also reported introduction of complementary feeding in $10 \%$ of infants less than 6 months and $19 \%$ of infants aged $4-5$ months. Bottle-feeding is reported as a norm even though not supported by health professionals. More than 1 in 5 babies under two months of age are bottlefed ${ }^{3}$. Similar findings could not be gathered from our study, as the patients were not followed up in the postnatal period. Our study was limited in this context. Early initiation of breast feeding, especially within one hour of birth, refers to the best practice recommended by $\mathrm{WHO}^{10}$. Early initiation of breast feeding will directly support progress toward achieving MDG through reducing neonatal mortality ${ }^{11}$.

In Pakistan breastfeeding is nearly universal although early initiation is not common. A survey done in 1990-91 revealed that only $8.5 \%$ of neonates were breastfed within the first hour and only $25.8 \%$ were breastfed on the day of delivery. The estimates rose to $27.2 \%$ and $65.5 \%$ in $2006-2007$, shows considerable improvement ${ }^{12}$.

The rationale of the study is that on extensive literature search study on factors associated with timely initiation of breast feeding has not been done locally and there is dearth of literature internationally as well. Therefore this study is designed to estimate the magnitude of these factors and to generate local data. Secondly some policy could be devised to highlight this issue thereby timely initiation of breast feeding could be initiated that will prevent maternal and neonatal morbidity and mortality.

\section{MATERIAL AND METHOD}

Women meeting the inclusion criteria admitted in the Department of Obstetrics and Gynecology, JPMC, Karachi, were enrolled in the study. It was a cross sectional study. Mothers were selected through non probability technique. Informed consent was taken after explaining the pros and cons, purpose and procedure of the study. The factors associated with timely initiation of breastfeeding like age of the mother, gestational age, parity, educational status, and occupation of the mother, mode of delivery, birth weight of the baby and gender of the baby were evaluated through face to face interview of the mothers and confirmed by hospital records and documented on structured Performa .

SPSS version 20 was used for data entry and analysis. Mean \pm SD was calculated for age of the women and gestational age at delivery, birth weight of the baby and birth interval. Frequency and percentages were calculated for gender of the baby, parity, educational level, mode of delivery, occupation of women, family monthly income and family structure (nuclear or extended). Effect modifiers were controlled through stratification of family monthly income, family structure (nuclear or extended) and birth interval to determine the effect of these on outcomes. Chi square test were applied and $\mathrm{p}$ value $=0.05$ was taken as significant.

\section{RESULTS:}

Mean age of the patients was 26.1 years ranging from (1835 ) years. Mean birth interval of the baby was 3.1years. Mean birth weight of the baby was $2.8 \mathrm{Kg}$. Mean gestational age of the Patients was 38.1 weeks. The gender distribution of the baby most of the babies were female $63(58 \%)$ other were male $45(42 \%)$. Out of 108 mothers $18(17 \%)$ were Illiterate, $40(37 \%)$ were Primary educated, $13(12 \%)$, were secondary, 10(9\%) were Intermediate and $27(25 \%)$ were graduated. The distribution of monthly income of mother women $38(35.2 \%)$ belong to middle class (monthly income $<25,000 \mathrm{RS}$.), $56(51.9 \%$ ) to upper middle class (monthly income $25,000-50,000 \mathrm{RS}$.) and only $14(13 \%)$ belong to higher class (monthly income $>50,000$ RS.). Fifty-Eight $(53.7 \%)$ women had multiparty. Most of the women were employed 76(70.3\%). Forty-two patients (38.9\%) women belonged to age 26-30 years with next majority between 21 25 years i.e. $36(33.3 \%)$ and only $5(4.7 \%)$ patients were more than 30 years of age. The gestational ages at delivery ranged from 34 to 42 weeks but most of them belong to gestational age more than 37 weeks i-e $80(74 \%)$. Most of the women 66(61\%) who have delivered baby through CSection. Effect modifiers were controlled through stratification of family monthly income, family structure (nuclear or extended) and birth interval to determine the effect of these on outcomes. Chi square test was applied and $p$ value $=0.05$ was taken as significant as shown on (Table2-3). There was significant association is seen family income and gender together affecting breast feeding(table2),significant association is seen family income and Parity, family income and gest.age affecting breast feeding(Table3 ) and significant association is also seen family structure and education, family structure and mode of delivery affecting breast feeding(Table-4).and birth interval and parity, birth interval and gest. Age are also showing significant association.

\section{DISCUSSION:}

Breastfeeding is advocated as an important child survival strategy by the World Health Organization especially in countries with poor socioeconomic background ${ }^{1-2}$. Breastfeeding is fundamental to the health and development of children and important for the health of their mother as well.

In Pakistan breastfeeding is nearly universal although early initiation is not common. A survey done in 1990-91 revealed that only $8.5 \%$ of neonates were breastfed within the first 
Factors Associated With Timely Initiation Of Breastfeeding Among Mothers In JPMC

\begin{tabular}{|c|c|c|}
\hline CHARACTERISTICS OF MOTHERS & FREQUENCY & PERCENTAGES (\%) \\
\hline \multicolumn{3}{|l|}{ Age } \\
\hline$<20$ Years & 25 & $23.1 \%$ \\
\hline 21-25 Years & 36 & $33.3 \%$ \\
\hline 26-30 Years & 42 & $38.9 \%$ \\
\hline$>30$ Years & 5 & $4.7 \%$ \\
\hline \multicolumn{3}{|l|}{ Parity } \\
\hline Primiparae & 42 & $38.9 \%$ \\
\hline Multiparae & 58 & $53.7 \%$ \\
\hline Grand multiparae & 8 & $0.4 \%$ \\
\hline \multicolumn{3}{|l|}{ Educational Status } \\
\hline Illiterate & 18 & $17 \%$ \\
\hline primary & 40 & $37 \%$ \\
\hline secondary & 13 & $13 \%$ \\
\hline Intermediate & 10 & $9 \%$ \\
\hline Graduate & 27 & $25 \%$ \\
\hline \multicolumn{3}{|l|}{ Gender of Baby } \\
\hline Male & 45 & $42 \%$ \\
\hline Female & 63 & $58 \%$ \\
\hline \multicolumn{3}{|l|}{ Birth Weight of baby } \\
\hline$<3 \mathrm{~kg}$ & 35 & $32 \%$ \\
\hline$>3 \mathrm{~kg}$ & 73 & $68 \%$ \\
\hline \multicolumn{3}{|l|}{ Mode of Delivery } \\
\hline Vaginal delivery & 42 & $39 \%$ \\
\hline Cesarean- sections & 66 & $61 \%$ \\
\hline \multicolumn{3}{|l|}{ Profession of Mothers } \\
\hline House wife & 32 & $29.7 \%$ \\
\hline Working & 76 & $70.3 \%$ \\
\hline
\end{tabular}

Table 1. Demographic and Obstetric Characteristics of Mothers $n=108$

\begin{tabular}{|c|c|c|c|c|c|c|c|c|}
\hline & $\begin{array}{l}\text { Age more } \\
\text { than } 20 \text { years }\end{array}$ & $\begin{array}{c}\text { Age less than } \\
20 \text { years }\end{array}$ & Total & P-value & $\begin{array}{c}\text { Baby Gender } \\
\text { Male }\end{array}$ & Female & Total & P-value \\
\hline $\begin{array}{l}\text { Family Income } \\
\text { Rs }<25,000 \\
\text { Rs } 25-50.000 \\
\text { Rs }>50,000\end{array}$ & $\begin{array}{c}20(18.5 \%) \\
47(43.5 \%) \\
13(12 \%)\end{array}$ & $\begin{array}{c}18(16.7 \%) \\
09(8.3 \%) \\
1(0.9 \%)\end{array}$ & $\begin{array}{l}38(35.2 \%) \\
56(51.9 \%) \\
14(13 \%)\end{array}$ & $0.001 *$ & $\begin{array}{l}30(27.8 \%) \\
10(9.3 \%) \\
05(4.6 \%)\end{array}$ & $\begin{array}{l}8(7.4 \%) \\
46(42.6 \%) \\
09(8.3 \%)\end{array}$ & $\begin{array}{l}38(35.2 \%) \\
56(51.9 \%) \\
14(13 \%)\end{array}$ & $0.000 *$ \\
\hline $\begin{array}{l}\text { Family Structure } \\
\text { Nuclear } \\
\text { Extended }\end{array}$ & $\begin{array}{c}35(33 \%) \\
45(42.5 \%)\end{array}$ & $\begin{array}{c}03(2.8 \%) \\
23(21.7 \%)\end{array}$ & $\begin{array}{l}38(35.8 \%) \\
68(64.2 \%)\end{array}$ & $0.004 *$ & $\begin{array}{l}16(14.8 \%) \\
29(26.9 \%)\end{array}$ & $\begin{array}{l}29(26.9 \%) \\
34(31.5 \%)\end{array}$ & $\begin{array}{l}45(41.7 \%) \\
63(58.3 \%)\end{array}$ & 0.276 \\
\hline $\begin{array}{l}\text { Birth Interval } \\
1-2 \\
3-4 \\
>5\end{array}$ & $\begin{array}{c}45(41.7 \%) \\
35(32.4 \%) \\
0(0 \%)\end{array}$ & $\begin{array}{c}16(14.8 \%) \\
10(9.3 \%) \\
2(1.9 \%)\end{array}$ & $\begin{array}{l}38(35.8 \%) \\
68(64.2 \%) \\
68(64.2 \%)\end{array}$ & 0.049 & $\begin{array}{l}25(23.1 \%) \\
13(12 \%) \\
2(1.9 \%)\end{array}$ & $\begin{array}{l}36(33.3 \%) \\
32(29.6 \%) \\
0(0 \%)\end{array}$ & $\begin{array}{l}61(56.5 \%) \\
45(41.7 \%) \\
2(1.9 \%)\end{array}$ & 0.079 \\
\hline
\end{tabular}

Table 2. Association of Family Income and Gender affecting breast feeding 
Beena Barkat, Shazia Naseeb, Razia Korejo

\begin{tabular}{|c|c|c|c|c|c|c|c|c|}
\hline & Parity $2 \&>2$ & Parity $<2$ & & & $\begin{array}{l}\text { Gest.Age Full } \\
\text { term baby } \\
37-42 \\
\end{array}$ & $<37$ Weeks & & \\
\hline $\begin{array}{l}\text { Family Income } \\
\text { Rs }<25,000 \\
\text { Rs } 25-50.000 \\
\text { Rs }>50,000\end{array}$ & $\begin{array}{l}15(41.7 \%) \\
39(18.5 \%) \\
12(0.9 \%)\end{array}$ & $\begin{array}{l}23(14.8 \%) \\
17(23.1 \%) \\
2(0.9 \%)\end{array}$ & $\begin{array}{l}38(35.2 \%) \\
56(51.9 \%) \\
14(13 \%)\end{array}$ & $0.002 *$ & $\begin{array}{l}28(25.9 \%) \\
46(42.6 \%) \\
06(5.6 \%)\end{array}$ & $\begin{array}{l}10(9.3 \%) \\
10(9.3 \%) \\
08(7.4 \%)\end{array}$ & $\begin{array}{l}38(35.2 \%) \\
56(51.9 \%) \\
14(13 \%)\end{array}$ & $0.011 *$ \\
\hline $\begin{array}{l}\text { Family Structure } \\
\text { Nuclear } \\
\text { Extended }\end{array}$ & $\begin{array}{l}25(23.1 \%) \\
41(38 \%)\end{array}$ & $\begin{array}{l}15(13.9 \%) \\
27(25 \%)\end{array}$ & $\begin{array}{l}45(37 \%) \\
68(63 \%)\end{array}$ & 0.820 & $\begin{array}{l}30(27.8 \%) \\
50(46.3 \%)\end{array}$ & $\begin{array}{l}15(13.9 \%) \\
13(12 \%)\end{array}$ & $\begin{array}{l}45(41.7 \%) \\
63(58.3 \%)\end{array}$ & 0.276 \\
\hline $\begin{array}{l}\text { Birth Interval } \\
1-2 \\
3-4 \\
>5\end{array}$ & $\begin{array}{l}45(41.7 \%) \\
20(18.5 \%) \\
1(0.9 \%)\end{array}$ & $\begin{array}{l}16(14.8 \%) \\
25(23.1 \%) \\
1(0.9 \%)\end{array}$ & $\begin{array}{l}61(56.5 \%) \\
45(41.7 \%) \\
2(1.9 \%)\end{array}$ & $0.009 *$ & $\begin{array}{l}51(47.2 \%) \\
29(26.9 \%) \\
0(0 \%)\end{array}$ & $\begin{array}{l}36(9.3 \%) \\
32(14.8 \%) \\
2(1.9 \%)\end{array}$ & $\begin{array}{l}61(56.5 \%) \\
45(41.7 \%) \\
2(1.9 \%)\end{array}$ & $0.005^{*}$ \\
\hline
\end{tabular}

Table 3. Association Family income with Parity of the Mothers and Gestational age

\begin{tabular}{|c|c|c|c|c|c|c|c|c|}
\hline & \begin{tabular}{l|} 
Education \\
Level: secon- \\
dary \& above
\end{tabular} & $\begin{array}{l}\text { Primary or } \\
\text { less }\end{array}$ & & & $\begin{array}{l}\text { Spontaneous } \\
\text { vaginal delivery }\end{array}$ & C section & & \\
\hline $\begin{array}{l}\text { Family Income } \\
\text { Rs }<25,000 \\
\text { Rs } 25,50.000 \\
\text { Rs }>50,000\end{array}$ & $\begin{array}{l}23(21.3 \%) \\
30(27.8 \%) \\
05(4.6 \%)\end{array}$ & $\begin{array}{l}15(13.9 \%) \\
26(24.1 \%) \\
9(8.3 \%)\end{array}$ & $\begin{array}{l}38(35.2 \%) \\
56(51.9 \%) \\
14(13 \%)\end{array}$ & 0.282 & $\begin{array}{l}15(13.9 \%) \\
24(22.4 \%) \\
03(2.8 \%)\end{array}$ & $\begin{array}{l}23(21.3 \%) \\
33(30.6 \%) \\
10(9.3 \%)\end{array}$ & $\begin{array}{l}38(35.2 \%) \\
56(51.9 \%) \\
14(13 \%)\end{array}$ & 0.445 \\
\hline $\begin{array}{l}\text { Family Structure } \\
\text { Nuclear } \\
\text { Extended }\end{array}$ & $\begin{array}{l}30(27.8 \%) \\
20(18.5 \%)\end{array}$ & $\begin{array}{l}15(13.9 \%) \\
43(39.8 \%)\end{array}$ & $\begin{array}{l}45(41.7 \%) \\
63(58.3 \%)\end{array}$ & $0.000 *$ & $\begin{array}{l}29(26.9 \%) \\
13(12 \%)\end{array}$ & $\begin{array}{l}16(14.8 \%) \\
50(46.3 \%)\end{array}$ & $\begin{array}{l}45(41.7 \%) \\
63(58.3 \%)\end{array}$ & $0.000 *$ \\
\hline $\begin{array}{l}\text { Birth Interval } \\
1-2 \text { (years) } \\
3-4 \\
>5\end{array}$ & $\begin{array}{l}40(37 \%) \\
10(9.3 \%) \\
0(0 \%)\end{array}$ & $\begin{array}{l}21(19.4 \%) \\
35(32.4 \%) \\
2(1.9 \%)\end{array}$ & $\begin{array}{l}61(56.5 \%) \\
45(41.7 \%) \\
2(1.9 \%)\end{array}$ & $0.000 *$ & $\begin{array}{l}24(22.2 \%) \\
17(15.7 \%) \\
1(0.9 \%)\end{array}$ & $\begin{array}{l}10(34.3 \%) \\
16(25.9 \%) \\
1(0.9 \%)\end{array}$ & $\begin{array}{l}61(56.5 \%) \\
45(41.7 \%) \\
2(1.9 \%)\end{array}$ & 0.936 \\
\hline
\end{tabular}

Table 4. Association of Family structure, birth interval and mode of delivery

hour and only $25.8 \%$ were breastfed on the day of delivery. The estimates rose to $27.2 \%$ and $65.5 \%$ in 2006-2007, shows considerable improvement ${ }^{12}$.

Promotion of early initiation of breast feeding is necessary for the prevention of avoidable deaths of children as different studies have proved that death rate is high when breast feeding started late ${ }^{13}$. It is shown from different studies that factors like antenatal visits, knowledge about breast feeding, number of live births, age of mother, mode of delivery, her education, occupation and economical status all have strong association with early initiation of breast feeding.

Breastfeeding is multi-factorial in nature and different factors will be at play depending on individual circumstances. We found similar results when we compared our study with a study which was done at Saudi Arabia in that study. The independent predictors of timely initiation were mothers who refrain from prelacteal feeding $(16 \%)$ and mother's residence rural area $(19.2 \%)$, absence of breast problems (12.7\%) and parity 2 or more $27 \% .10$ other factors were age $>20$ years $(11.34 \%)$, educational level secondary and above $(22 \%)$, house wife $(11.8 \%)$, male sex of infant $(13.4 \%)$. Full term $(12.6 \%)$, mode of delivery; spontaneous vaginal delivery $(13 \%)^{14}$.

Sharma A et $\mathrm{al}^{15}$ also found significant association similar to our study between early initiation of breast feeding with education, occupation and economic status of the mother but reported no significant association with maternal age, type of family, family size and live birth. Setegn et al ${ }^{16}$ also reported same as formal educated women were 1.4 times as likely to initiate breast feeding with first hour of delivery.

In many developing countries particularly in Asia, the converse is true and extended lactation is more frequent in poor uneducated women in rural areas, and in urban areas higher level of education are negatively associated with breast feeding initiation and duration ${ }^{17-18}$.

Other studies in Jeddah, Saudi Arabia by Fida and Al-Aama (2003) and Shawky and Abalkhail (2003) $)^{19-22}$ included 21\% of university graduated women (Fida \& Al-Aama, 2003), $39.5 \%$ illiterate women and $88 \%$ housewives (Shawky \& Abalkhail, 2003) ${ }^{22-25}$. A more recent study, which also was done in a private hospital in Jeddah, Saudi Arabia (Mosalli et al, 2012) $)^{23}$ reported fewer multiparous (54\%), graduated (24\%), and caesarean delivery (31\%) women compared with current study. However, Mosalli et al. (2012) reported similar percentages of housewives $(78 \%)$ and similar age group distribution.

Many studies have indicated that a woman's obstetric experience may influence her breast-feeding behaviors. Our study shows positive association with vaginal delivery while some researchers ${ }^{24}$ have found no association between mode 
of delivery and breastfeeding, but others ${ }^{25}$ have reported a negative association between cesarean delivery and breastfeeding initiation but not duration once breast feeding has commenced.

\section{Conclusion:}

Hence we conclude that age of mother (being more than 20 years), having two or more children, having at least secondary level of education, having male last child, having last birth by spontaneous vaginal delivery and being a house wife were factors responsible for timely initiation of breast feeding in our study.

\section{Recommendation:}

In the light of our findings we recommend that breastfeeding education should be in conjunction with obstetrics. Hence two clinics should be merged into one at Jinnah Postgraduate Medical Center Karachi.

\section{REFERENCES:}

1. Millenium Development Goals. Available from:http://www .who.int/topics/millennium_development_goals/en/ Accessed on May 29201.

2. National Institute of Population Studies. Pakistan Demographic and Health Survey 2012-2013[Internet]. Islamabad: National Institute of Population Studies; 2013. Available from: http://www.nips.org.pk. Accessed on November 25,2014.

3. Suresh S, Sharma KK, Saksena M, Thukral A,Agarwal R, Vatsa M. Predictors of breastfeeding problems in the first postnatal week and its effect on exclusive breastfeeding rate at six months: experience in a tertiary care centre in Northern India. Indian J Public Health 2014; 58: 270-3.

4. The Baby Friendly Hospital Initiative [Internet].UNICEF. Available from: http://www.unicef.org/programme/breastfeeding/baby.htm. Accessed on December 5, 2014.

5. Khan M, Akram DS. Effects of baby-friendly hospital initiative on breast-feeding practices in sindh. J Pak Med Assoc 2013; 63(6): 756-9

6. World Health Organization. The optimal duration of exclusive breastfeeding: report of an expert consultation Geneva: WHO, 2001. http:// www .who.int/nutrition/publications/optimal_ duration_of_exc_bfeeding_report_eng.pdf. Accessed on 29 May 2015

7. Gartner LM, Morton J, Lawrence RA, Naylor AJ,O'Hare D, Schanler RJ, et al. American Academy of Pediatrics Section on Breastfeeding. Breastfeeding and the use of human milk. Pediatrics 2005; 115(2): 496-506

8. Ahmad MO, Sughra U, Kalsoom U, Imran M, Hadi U. Effect of antenatal counselling on exclusive breastfeeding. J Ayub Med Coll Abbottabad 2012; 24(2): 116-9.

9. Dhandapany G, Bethou A, Arunagirinathan A, Ananthakrishnan S. Antenatal counseling on breastfeeding -- is it adequate? A descriptive study from Pondicherry, India. Int Breastfeed J 2008; 3(1): 5 .
10. WHO Breastfeeding-early initiation :World Health Organization;2012 http//www.who.int/Elena/title/earlybreastfeeding/en/access 5 April 2013

11. Khan J,VeselL,BahlR, MartinesJc.,Timing of breastfeedindg during first month of life: Effect on neonatal mortality and morbidity-a systemic review and meta analysis:mat and child nutr. 2015; 19(3): 468-79.

12. National Institute of Population Studies. Pakistan Demographic and Health Survey 2006-2007 [Internet]. Islamabad: National Institute of Population Studies; 2013.Available from: http:// www.healthkp.gov.pk/downloads/PDHS.pdf Accessed on 29 may 2015.

13. Santos et al .Avoidable deaths in first four years of life among children in 2004 pelotos(brazil birth cohort study.'ca demos de saude public..2011; 27: 185-97

14. El-Gilany AH, Sarraf B, Al-Wehady A. Factors associated with timely initiation of breastfeeding in Al-Hassa province, Saudi Arabia. East Mediterr Health J. 2012; 18(3): 250-4.

15. Sharma A et al.factors associated with early ignition of breast feeding among mothers of tribal areas of Madhya paradesh:a community based,India: a community based cross sectional study; int J community med.public health. 2017; 3(1): 1949.

16. Setengn T,Gerbaba M, BelachewT.Determinants of timely initition of breast feeding among mothers in Goba woreda,south east Ethiopia: A cross sectional study.BMC public health. 2011; 11(1): 217

17. Penticen.Extended breast-feeding and growth in rural china.Nute.Rev. 114; 52: 144-48.

18. Rogers I,Emmett P,GoldingJ. The incidence and duration of breast feeding.Early Hum Devel.1997; 49(Supplement): 143155 .

19. Truman, Edwin M. Sovereign wealth funds: the need for greater transparency and accountability. Peterson Institute for International Economics, 2008.

20. Al-Mazrou, Y. Y., K. M. S. Aziz, and M. Khalil. "Breastfeeding and weaning practices in Saudi Arabia." Journal of tropical pediatrics. 1994; 40(5) 267-71.

21. Fida, Nadia M., and Jumama Y. Al-Aama. "Pattern of infant feeding at a University Hospital in Western Saudi Arabia." Saudi medical journal. 2003; 24(7); 725-9.

22. Shawky, Sherine, and Bahaa A. Abalkhail. "Maternal factors associated with the duration of breast feeding in Jeddah, Saudi Arabia." Paediatric and perinatal epidemiology. 2003; 17(1); 91-6.

23. Mosalli, Rafat, et al. "Perceived barriers to the implementation of a baby friendly initiative in Jeddah, Saudi Arabia." Saudi medical journal. 2012; 33(8); 895-900.

24. Scott J A,Landers MCG,Hughes RM,Binns CW.factors associated with breast feeding at Discharge and duration of breast feeding JPediatar child Health. 2001; 37(3): 254-261.

25. Perez-EscamillaR, Maulen-RadovanI, Dewey KG. The association between caesarean delivery and breast feeding outcome among maxicon women. Am J public Health. 1996: 86(6); 832-6. 